\title{
CARE REGIO - Digital Transformation and Technology in Nursing Care
}

\author{
Dominik FUCHS ${ }^{\mathrm{a}, 1}$, Ann-Kathrin WAIBEL ${ }^{\mathrm{b}}$, Maximilian KARTHAN ${ }^{\mathrm{b}}$, Nadine \\ SEIFERT $^{\mathrm{b}}$, Michael ÖRTL ${ }^{\mathrm{b}}$, Sabrina BETHGE ${ }^{\mathrm{c}}$, Gina FISCHER ${ }^{\mathrm{b}}$, Luca \\ WASCHBÜSCH $^{\mathrm{b}}$, Steffen NETZBAND ${ }^{\mathrm{d}}$, Frank KRAMER ${ }^{\mathrm{d}}$, Andreas MAHLER ${ }^{\mathrm{c}}$, \\ Alexandra TEYNOR ${ }^{\mathrm{e}}$, Dominik MERLI ${ }^{\mathrm{e}}$, Elisabeth Veronica MESS ${ }^{\mathrm{e}}$, Jennifer \\ ÖTTINGER ${ }^{\mathrm{b}}$, Stefanie SCHMID ${ }^{\mathrm{a}}$, Amelie SCHEU ${ }^{\mathrm{b}}$, Walter SWOBODA ${ }^{\mathrm{b}}$ and Petra \\ FRIEDRICH $^{\mathrm{a}}$ \\ ${ }^{a}$ University of Applied Sciences Kempten, \\ ${ }^{\mathrm{b}}$ University of Applied Sciences Neu-Ulm, \\ ' Augsburg University Hospital, \\ d University of Applied Sciences Augsburg, \\ ${ }^{\mathrm{e}}$ University of Augsburg
}

\begin{abstract}
Digital technologies have the potential to improve the quality of nursing care. CARE REGIO is a Bavarian joint research project for digital transformation and technology in nursing care. The project goals are supporting the nursing staff, saving time, improving the quality of care as well as increasing the quality of life and safety of those in need of care. In Phase 1 of the project, literature and stakeholder analyses, and qualitative surveys were carried out. Subsequently, central fields of action were defined for Phase 2 of the project. CARE REGIO can make a significant contribution to evaluating existing digital solutions, developing new solutions, and accelerating their implementation into practice.
\end{abstract}

Keywords. Digitization, nursing care, care transition report, assistive systems, care data lake, nursing wiki

\section{Introduction}

Digital technologies have the potential to improve the quality of nursing care and make work processes more efficient. In its "State of the World's Nursing Report - 2020" [1], the World Health Organization (WHO) urges that the opportunities offered by digital health technology should be leveraged. The widespread use of technologies in nursing care still faces major challenges, such as financial hurdles, the lack of technically oriented training for caregivers, ensuring data privacy and data security, and the fear of losing one's job [2,3]. Currently, the use of isolated technical solutions prevails in German-speaking countries, which results in considerable additional administrative work for nursing staff [4]. When dealing with patient data, it is of the utmost importance to handle the collected patient-relevant data in a manner that complies with data protection regulations [5]. The CARE REGIO project aims to promote the digital

${ }^{1}$ Corresponding Author, Dominik Fuchs, University of Applied Sciences Kempten, Bahnhofstraße 6 87435 Kempten, Germany; E-mail:dominik.fuchs@hs-kempten.de. 
transformation of care by implementing and evaluating broad and collaborative efforts. The project network consists of the three Bavarian Universities of Applied Sciences of Augsburg (UAA), Kempten (UAK) and Neu-Ulm (UAN), as well as the University of Augsburg (UA) and the Augsburg University Hospital (AUH). The project is funded by the Bavarian State Ministry of Health and Care (StMGP) and will take place in two phases: The goal of the one-year Phase 1, which was completed in September 2020, was to identify suitable fields of action through literature and market analysis, as well as through the project's own surveys, interviews, process and stakeholder analysis. The steps and results that led to selected central fields of action are presented below.

\section{Methods}

\subsection{Qualitative Expert Interviews}

Qualitative surveys were conducted at AUH and three cooperating nursing facilities. The focus was on the transfer of care data, the technical equipment for data transfer, and the communication servers used. Furthermore, the experts were asked about the education and training behavior of nurses. Specifically, if self-directed (online) learning could achieve better learning results than existing offline approaches. Corresponding guidelines for the interviews were created. In addition, a market analysis was conducted for digital learning offerings in the nursing context. The (technically focused) survey in the AUH focused on a query of the status quo concerning the nursing documentation systems and communication servers used. Basic requirements, wishes and concerns regarding partial digital automation of the care transition report (CTR) were also inquired. The survey of the cooperating care facilities focused on currently used data transfer systems, the respective service providers/vendors, currently used data formats, and existing interoperability standards. Likewise, future planned new acquisitions and changes were inquired.

Another independent series of interviews was conducted with two experts, which accompanied participants in a test series in which ten outpatient seniors tested a devicesupported leg training for fall prevention over two weeks. For the survey, an interview guideline was developed in which facilitating factors and obstacles regarding the feasibility (implementation) and acceptance of leg training and an app-based assessment of fall risk were asked [6]. The expert interviews were evaluated using a qualitative content analysis based on Mayring [7].

\subsection{Analysis of the Patient Transition Process}

In a process analysis, the patient transfer process at the AUH was analyzed. The internal clinical processes and the processes in connection with the external facilities were examined. The goal was to determine the current status of the processes and to derive potentials for process improvement. Therefore, clinic staff and staff from external facilities were interviewed. The interviews were conducted and recorded using an interview guide. The results were then evaluated using qualitative methodology according to Mayring [7], and a process model was created from the results using Business Process Management Notation (BPMN 2.0). In a stakeholder analysis, the stakeholders significantly involved in the transition of the CTR were considered to record or define initial requirements and the resulting benefits. 


\section{Results}

\subsection{Qualitative Expert Interviews}

The survey on the transfer of care data in three nursing facilities and the AUH determined that the transfer of nursing-relevant patient data from the analogous transfer forms to the electronic documentation is associated with a high time expenditure. As a guideline, "over 30 minutes" was mentioned. All of the facilities surveyed in the technically focused interviews used different systems for internal data transfer. External digital communication of nursing data did not take place as there is no data protection-compliant connection. According to the current status, data is transferred in advance by telephone and then only in printed form or as a fax. According to the respondents, a completely digital solution would mean significant added value for nursing care in the medium to long term, including reduced administrative effort and better preparation. Therefore, all facilities were in favor of an automated, electronic exchange of care data integrated into the respective documentation systems.

In the interviews about digital learning offerings in the nursing context, the potential success was deemed considerable and potentially larger with younger than older employees. Market analysis revealed that there is currently no project with a comprehensive digital compendium, a so-called 'nursing wiki'. Corresponding Germanlanguage sources are currently hardly available, outdated, or no longer accessible.

In the qualitative analysis of the expert interviews regarding assistive systems for fall prevention, the following results could be identified: The technology-assisted movement training was well received. With regard to usability, the ease of use of the technical movement trainer was cited as a beneficial factor. Another advantage from the point of view of an expert was that the test persons could exercise in a seated position, so that the risk of injury can be minimized even without supervision. The adjustability of the pedaling resistance and the choice of speed allowed subjects to adapt the workout to their individual performance level and increase it gradually, which can also be considered a facilitating factor. Limited space in the participants' own homes was cited as a potential barrier. In addition, transporting the device was considered too difficult for older people without assistance due to its weight.

\subsection{Analysis of the Patient Transition Process}

One significant result of the process analysis was that there are many media discontinuities in the transition process, which means that work has to be repeated. Ambiguities regarding the responsibility of certain tasks can be more clearly regulated in a digitally recorded process. A process model was created with BPMN 2.0. The process modeling showed that there would be valuable opportunities for process optimization with regard to the way data and information are exchanged. In a subsequent analysis of the 'high-level activities', which focused on the transition of the CTR, it was possible to define possible requirements. These included automatic or manually confirmed data import and the ability to structure, filter, and search the data. In a stakeholder analysis, it could be shown that each stakeholder group could benefit from the digitization of the CTR. 


\section{Discussion and Future Directions}

The surveys on the topic of patient discharge and transition management revealed a currently high time expenditure in the preparation of CTR and subsequent transition of patients. Furthermore, a lack of suitable software and interfaces for cross-sector digital communication was identified. The need to comply with data protection guidelines was also recognized. Accordingly, time savings are also a key funding factor following successful conversion to digital processes. In assistive systems and care transition, the high financial, time and personnel costs involved in implementation were mentioned as existing obstacles. The expert interviews and process analysis revealed issues, both for facilitating processes and the existing hurdles and obstacles. This applies in particular to the opportunities and hurdles identified in the area of digitization of discharge and transfer management and assistive technologies for fall prevention $[3,8]$.

Following our analysis and surveys, the central fields of action for further work in Phase 2 were identified and narrowed down based on the results. In addition to the crosscutting issue of scientific support (including data protection and ethics), the project has decided on the following key fields of action for Phase 2 of the project: Digitization of the CTR, assistive systems (in fall prevention), an online training and continuing education offering ('nursing wiki'), and a digital care research database (a nursing data lake) to increase the synchronization of data collection and transfer (interoperability and standardization) between care facilities. An important aspect that has hampered the sustainable use of similar projects is the networking of nursing processes at the data level. CARE REGIO, therefore, intends to make use of the German Telematics Infrastructure [9] and thus enable a secure and legally compliant form of documentation and forwarding of patient-relevant data in the field of nursing. Project developments will be made accessible and will be distributed through Open Access (e.g., 'nursing wiki') and/or Open Source in terms of software-related advancements.

\section{Acknowledgment}

This project is supported by funds from the Bavarian State Ministry of Health and Care (Bayerisches Staatsministerium für Gesundheit und Pflege - StMGP).

\section{References}

[1] Organization WH. State of the world's nursing 2020: investing in education, jobs and leadership. 2020.

[2] Kuhlmey A, Blüher S, Nordheim J, Zöllick J. Technik in der Pflege-Einstellungen von professionell Pflegenden zu Chancen und Risiken neuer Technologien und technischer Assistenzsysteme. Zentrum für Qualität in der Pflege, Berlin. 2019.

[3] Merda M, Schmidt K, Kähler B. Pflege 4.0-Einsatz moderner Technologien aus der Sicht professionell Pflegender. Forschungsbericht für die BGW, Hamburg. 2017.

[4] Rösler U, Schmidt K, Merda M, Melzer M. Digitalisierung in der Pflege. Wie intelligente Technologien die Arbeit professionell Pflegender verändern. Stand: März 2018, 1. Aufl. Berlin2018. 72 S. p.

[5] Ethikrat D. Big Data und gesundheit-Datensouveränität als informationelle Freiheitsgestaltung. 2017.

[6] Fuchs D, Tiebel J, Friedrich P. Device-supported training and assessment for fall prevention of community-dwelling elderly: a pre-post mixed methods study. Procedia Computer Science. 2020;176:2322-31.

[7] Mayring P. Qualitative Inhaltsanalyse. Grundlagen und Techniken, 12. Aufl. Beltz. Weinheim; 2015.

[8] Gesundheit Bf. Informations- und Kommunikationstechnologie für die Pflege. ePflege. Berlin2017. gematik. Telematikinfrastruktur - das digitale Gesundheitsnetz für Deutschland: gematik; 2021 [cited 2021 29.09.2021]. Available from: https://www.gematik.de/telematikinfrastruktur. 